\title{
Applying Technical Analysis of Stock Trends to Trading Strategy of Dynamic Portfolio Insurance
}

\author{
Jung-Bin $\mathrm{Li}^{1}$, Sheng-Hsiu $\mathrm{Wu}^{1}$, Mu-Yen Chen ${ }^{2}$ and An-Pin Chen ${ }^{1}$ \\ ${ }^{1}$ Institute of Information Management, National Chiao Tung University \\ ${ }^{2}$ Department of Accounting, National Changhua University of Education. \\ ${ }^{1}\left\{\right.$ jbli, apc\}@iim.nctu.edu.tw, ${ }^{2}$ chenmy@cc.ncue.edu.tw
}

\begin{abstract}
In the trading operation of dynamic portfolio insurance, TIPP (Time Invariant Portfolio Protection), when adjusting active assets, only considers the scale of asset of that time regardless of how market trend proceeds. In other words, TIPP is clumsy in evading loss and pursuing profits. This study makes use of the predictability of artificial neural network, via market trend analysis and the learning of historical data, to find out the most optimized Multiplier of TIPP in various situations so as to optimize dynamic portfolio insurance. This study utilizes two kinds of artificial neural networks. One is to employ the price, quantity, and tendency technical index as the input item to predict the future rise or drop as the output item. The other is to employ the various technical indexes when MACD crossed on that day to serve as the input item, and the output items are the future range and days of rise and drop. The statistics show that the profitability of the prediction module of crossed MACD is better than the artificial neural networks; both are better than the traditional strategy operation of TIPP.
\end{abstract}

Keyword: neural network, genetic algorithm, portfolio insurance

\section{Research motivation and objectives}

The liberalized financial market has given impetus to the prosperity of stock market. Financial commodities such as bonds, futures, and options can be considered as hedging tools. Therefore, making appropriate use of such tools to lower investment risk while sustaining stable profitability by operations such as portfolio insurance is an issue which worth in-depth discussion.

The purpose of portfolio insurance is to control the risk of investment portfolio at a reasonable level and protect the investment from losses of the portfolio net value while making profits when the market trend goes up. Portfolio insurance is relatively a good investment strategy for conservative and risk-reluctant investors especially when the stock trend is veiled and obscure. This strategy is especially suitable for the large funds such as balanced fund, insurance fund, retirement fund, investment trust, and etc.

In dynamic portfolio insurance strategies, time invariant portfolio protection (TIPP) adjusts the weights of active and reserve asset investments to make profit and guarantee principal. Considering of the trading cost, dynamic adjustment of the ratio of investment portfolio is not feasible in the traditional way. Adjustment of active assets is done by periodical review of the cushion. However, such measure considers the total asset value only. Taking active asset in stock investment as an example, the total asset shrinks in bear market based on the set investment ratio. Contrarily the cushion increases along with the total asset in bull market. In other words, TIPP has shortcoming in active reaction to the market fluctuation.

Some parameters of TIPP model are usually set according to managers' personal experiences, which may cause inconsistent performances in different cases. Hence this study attempts to find an optimized way of setting these parameters by a systematic methodology. By analyses of general index trend, forecasts are done and mapping operations are executed to expand profit and reduce loss. Namely if technical indices are applied with the forecast ability of neural networks, the most appropriate multiplier of TIPP under every condition can be found through historical data learning. Optimization of dynamic portfolio insurance is then achieved.

\section{Model design}

This study applies neural network to an operation strategy of dynamic portfolio insurance, time invariant portfolio protection (TIPP), to forecast the future up/down trend. In this study, the multiplier is adjusted according to the output of neural network. Target of risk-based capital is TaiEX and other investment portfolio including futures with equivalent effect, and target of non-risk-based capital is term deposit or bonds with equivalent effect. We use two types of neural networks $(\mathrm{NN})$ : one takes opening and closing prices, highest and lowest prices, trade volume, average 5-day price and volume, 5-day RSI, 5-day DMI, 5-day KD, MACD, and other indices as network input items, and the trend forecast is network output. The other NN takes the technical indices after MACD intersects as network input, and network output factors are forecasts of future up/down scale and length of up/down trend period. A simulation is done by predictions of these two NNs. The performance of this 
model is compared with traditional TIPP strategy afterward.

Our testing period covers uptrend interval (1999/02/02 2000/02/29), consolidation interval $(1999 / 09 / 01 \sim 1999 / 12 / 28)$, and downtrend interval $(2000 / 03 / 01 \sim 2001 / 02 / 01)$, which makes this model more comprehensive in dealing with different conditions. Fig. 1 illustrates the index fluctuation in the testing period.

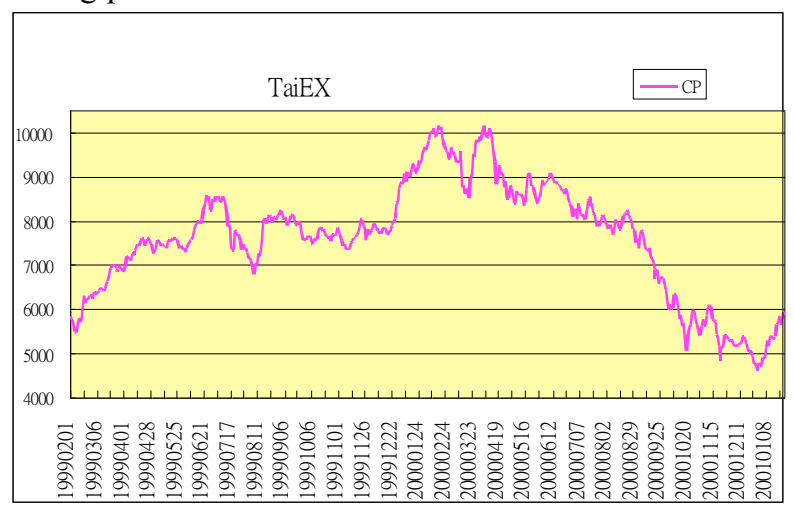

Fig.1 Testing period of study

\subsection{Model implementation}

\section{- Technical index neural network}

This study adopts Multi-Layer Perceptrons (MLPs), and applies back propagation algorithm to build neural network model. In our model, two neural networks are used to forecast price trend. The network of first stage adopts technical indices as input to forecast the moving trend of five-day average price.

With 1200 entries of training data, 500 entries of cross validation data, and 532 entries of testing data, there is a feature that the average price falls behind. If the five-day average price forecast is moved one day earlier, its linear correlation coefficient of network forecast is 0.389. Furthermore, if the forecast is simplified to only upward or downward, the forecast accuracy reaches $64.4 \%$.

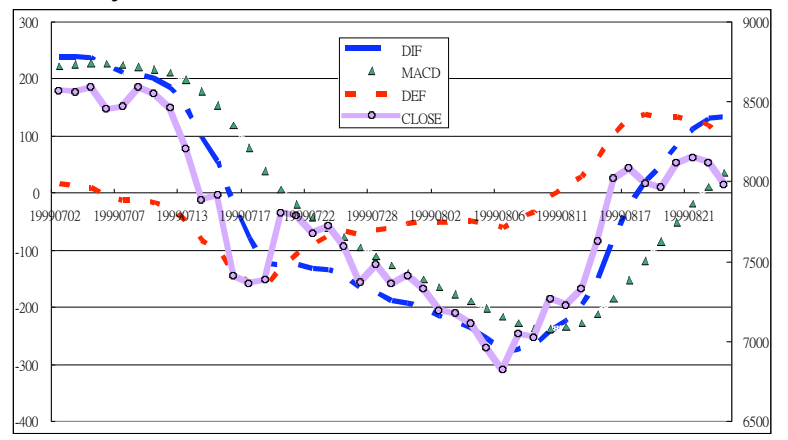

Fig. 2 Price fluctuation after MACD crossovers

\section{- MACD crossover neural network}

As shown in Fig. 2, it is noteworthy that the stock index has substantial fluctuation after MACD crossovers. Therefore this study adopts neural network to predict the amount of gain/loss of stock index and the length of up/down trend interval after MACD crossovers. Such information will be a reference for adjusting the TIPP multiplier. The framework of our model is decribed as below:

(1) Data source: From 1993/03/10 to 2001/01/03, there are 144 entries of TaiEX data with MACD intersection.

- $1993 / 03 / 10 \sim 1997 / 08 / 25: 90$ entries of MACD intersection as training data.

- 1997/08/28 1999/01/25: 22 entries of MACD intersection for cross validation.

- 1999/02/10 2001/01/03: 32 entries of MACD intersection as testing data.

(2) Input and output data: this study takes trade price, volume, and technical indices of the days when MACD intersects as the input items of neural network. Output value is the level and number of days from MACD crossover to the maximum of the open interval.

\subsection{Model assumptions and operation strategy}

This study assumes the floor of TIPP is $70 \%$, i.e., the exposure to risk-based capital is $30 \%$ when the multiplier is one. The traditional TIPP review cycle is on a monthly basis. The TIPP operation strategy made by the proposed neural network model is reviewed weekly, hence the cycle length is five trade days. In order to compare with the performance of even shorter cycles, this study also analyzes 4-day operation strategy because of the forementioned 3.8-day neural network forecast result. Outcomes of different parameters are compared afterward.

Operation strategy of technical index neural network

The TIPP opeation strategies of our neural network forecast include four conditions:

(1) When the forecast is bullish, TIPP multiplier is set to be one. In other words, $30 \%$ of investment is on risk-based capital.

(2) When the forecast is bearish, TIPP multiplier is set to be zero. In other words, all investment is on preserved asset.

(3) If the investment gains profit, the quota of guaranteed principle can be raised.

(4) If the investment causes loss, the quota of guaranteed principle remains unchanged.

\section{- Operation strategy of MACD crossovers}

The TIPP operation strategies of TIPP crossover neural network include four conditions:

(1) If the MACD crosses below its signal line when there is no risk-based capital investment, the strategy is kept until the next cycle.

(2) If the MACD crosses below its signal line when risk-based capital is in portfolio, the multiplier is set as zero. In other words, all investment in portfolio changes to preserved asset. Operation strategy is reviewed after the next cycle.

(3) If the MACD crosses above its signal line and the technical index neural network also makes a bullish forecast, the multiplier is set as two. In 
other words, risk-based capital investment is adjusted to be $60 \%$ of the portfolio. Operation strategy is reviewed after the next cycle.

(4) If the MACD crosses above its signal line and the technical index neural network makes a bearish forecast, the strategy is kept unchanged until the next cycle.

\section{- Operation strategy of MACD crossovers (multiplier $=4$ )}

To further compare with the up/down trend of TaiEX, this study attemps to simulate TIPP investments close to and larger than the total asset with MACD crossover neural network. If the multiplier is four, operation strategie is different from the previous mode when the MACD crosses above its signal line and the technical index neural network also makes a bullish forecast. In this case, risk-based capital investment is adjusted to be $120 \%$ of the portfolio.

\section{- Assumptions of transaction cost and dividend of preserved asset}

This study makes the following assumptions regarding to transaction cost, dividend of preserved asset, and cost of margin trading:

(1) Transaction cost: it is assumed that the target of risk-based captial is an investment combination with equivalent effect of TaiEX. Transaction cost including service charge and tax is $0.26 \%$.

(2) Dividend of risk-based capital: the target of preserved asset is term deposit or bond with equivalent effect. The annual interest rate of dividend is assumed $2 \%$.

(3) Cost of margin trading: When operations are done under the situation of multiplier equals to four, the investment in risk-based capital is greater than the total value of assets. Hence the cost of margin trading has to be considered. The annual interest rate is assumed $6 \%$.

\section{Performance analysis}

This study takes 532 entries of data from 1999/02/02 to $2001 / 02 / 01$ as testing data for validation. In our empirical study, standard TIPP, technical index neural network, and MACD crossout neural network are adopted. Simulations are made for review cycles of four and five days, respectively, and their performances are analyzed and discussed.

\subsection{Comparison of three models}

Three types of TIPP operation strategies are compared, including traditional TIPP, technical index neural network (ANN), and MACD crossover neural network. Comparisons are made by 4-day prediction model, 5-day prediction model, and whether the trading cost is included, i.e., four comparison are listed below.

\section{- Simulation of 4-Day prediction}

Performance comparison: MACD $>$ ANN $>$ TIPP
Table 1 Validation of 4- and 5-day prediction modes

\begin{tabular}{|c|c|c|c|c|c|c|}
\hline \multicolumn{7}{|c|}{ 4-day prediction with trading cost } \\
\hline & $\begin{array}{c}\text { Traditional } \\
\text { TIPP }\end{array}$ & \multicolumn{2}{|c|}{ ANN } & \multicolumn{2}{c|}{$\begin{array}{c}\text { MACD } \\
\text { crossover }\end{array}$} \\
\cline { 2 - 7 } & Profit\% & $\begin{array}{c}\text { Cpt } \\
\text { Psrv \% }\end{array}$ & Profit\% & $\begin{array}{c}\text { Cpt } \\
\text { Psrv } \%\end{array}$ & Profit\% $\%$ & $\begin{array}{c}\text { Cpt } \\
\text { Psrv \% }\end{array}$ \\
\hline Uptrend & $17.4 \%$ & $83.3 \%$ & $17.6 \%$ & $82.7 \%$ & $33.6 \%$ & $93.5 \%$ \\
\hline Downtrend & $-10.9 \%$ & $70.8 \%$ & $-4.3 \%$ & $71.5 \%$ & $1.2 \%$ & $72.6 \%$ \\
\hline Consolidation & $2.0 \%$ & - & $5.0 \%$ & - & $9.1 \%$ & - \\
\hline & $5-$ day prediction with trading cost & \\
\hline Uptrend & $17.5 \%$ & $83.3 \%$ & $14.6 \%$ & $82.0 \%$ & $27.3 \%$ & $91.1 \%$ \\
\hline Downtrend & $-10.9 \%$ & $70.8 \%$ & $1.9 \%$ & $73.2 \%$ & $1.9 \%$ & $76.0 \%$ \\
\hline Consolidation & $2.0 \%$ & - & $2.1 \%$ & - & $7.9 \%$ & - \\
\hline
\end{tabular}

Note: "Cpt Psrv" stands for capital preservation for short.

\section{Simulation of 5-Day prediction}

In uptrend interval, MACD is better than TIPP, and TIPP is slightly better than ANN. In downtrend interval, MACD $>$ ANN $>$ TIPP.

\subsection{Comparison of three models with multiplier $=\mathbf{4}$}

In this section, we raise the multiplier of TIPP to four, and the analysis of simulations is described below.

\section{Simulation of 4-Day prediction}

Performance comparison: MACD $>$ ANN $>$ TIPP

Table 2 Validation of 4- and 5-day prediction modes with multiplier $=4$

\begin{tabular}{|c|c|c|c|c|c|c|}
\hline \multicolumn{7}{|c|}{ 4-day prediction with trading cost } \\
\hline & $\begin{array}{c}\text { Traditional } \\
\text { TIPP }\end{array}$ & \multicolumn{2}{|c|}{ ANN } & \multicolumn{2}{c|}{$\begin{array}{c}\text { MACD } \\
\text { crossover }\end{array}$} \\
\cline { 2 - 7 } & Profit\% & $\begin{array}{c}\text { Cpt } \\
\text { Psrv } \%\end{array}$ & Profit\% & $\begin{array}{c}\text { Cpt } \\
\text { Psrv \% }\end{array}$ & Profit\% & $\begin{array}{c}\text { Cpt } \\
\text { Psrv \% }\end{array}$ \\
\hline Uptrend & $17.4 \%$ & $83.3 \%$ & $17.6 \%$ & $82.7 \%$ & $61.0 \%$ & $112.7 \%$ \\
\hline Downtrend & $-10.9 \%$ & $70.8 \%$ & $-4.3 \%$ & $71.5 \%$ & $4.1 \%$ & $77.1 \%$ \\
\hline Consolidation & $2.0 \%$ & - & $5.0 \%$ & - & $18.4 \%$ & - \\
\hline \multicolumn{7}{|c|}{5 -day prediction with trading cost } \\
\hline Uptrend & $17.4 \%$ & $83.3 \%$ & $14.6 \%$ & $82.0 \%$ & $51.5 \%$ & $108.4 \%$ \\
\hline Downtrend & $-10.9 \%$ & $70.8 \%$ & $1.9 \%$ & $73.2 \%$ & $5.3 \%$ & $81.7 \%$ \\
\hline Consolidation & $2.0 \%$ & - & $2.1 \%$ & - & $17.6 \%$ & - \\
\hline
\end{tabular}

\section{Simulation of 5-Day prediction}

In uptrend interval, MACD is better than TIPP, and TIPP is slightly better than ANN. In downtrend interval, MACD $>$ ANN $>$ TIPP.

\section{Comparison of MACD crossover (multiplier $=4$ ) and TaiEX}

An analysis is made to compare the performance of actual TaiEX and MACD crossover neural network with multiplier equal to four. In our sampling period, the uptrend interval is between 1999/02/02 and 2000/02/29. During this interval, TaiEX booms from 5749.64 points to 9435.94 points, the rate of change is $64.114 \%$, which is greater than the performance of MACD crossover prediction model with multiplier equal to two (31.948\%). If the TIPP multiplier is raised from two to four, then the model's profitability is $64.114 \%$. Namely, if the trend of stock index is effectively observed and handled, the profitability of this model can reach that of TaiEX by magnifying its TIPP multiplier. The performance of each model is 
listed in Table 3.

Table 3 Comparison of TaiEX and MACD crossover model (multiplier $=4$ )

\begin{tabular}{|l|c|c|}
\hline \multicolumn{1}{|c|}{ Multiplier $=4$} & $\begin{array}{c}\text { Profit\% of } \\
\text { downtrend } \\
\text { interval }\end{array}$ & $\begin{array}{c}\text { Profit } \% \text { of } \\
\text { uptrend } \\
\text { interval }\end{array}$ \\
\hline TaiEX & $-39.128 \%$ & $64.114 \%$ \\
\hline 4-day prediction & $5.251 \%$ & $62.869 \%$ \\
\hline 4-day prediction; trading cost included & $4.129 \%$ & $61.403 \%$ \\
\hline 5-day prediction & $5.978 \%$ & $52.770 \%$ \\
\hline 5-day prediction; trading cost included & $5.279 \%$ & $51.534 \%$ \\
\hline
\end{tabular}

Uptrend interval: 4-day prediction mode is closer to buy and hold profitability of the TaiEX than 5-day prediction mode, even the trading cost is included.

Downtrend interval: the profitability of 5-day prediction mode is better than that of 4-day mode. Contrary to the loss of buy and hold strategy, both 4-day and 5-day MACD crossover model are profitable even the trading cost is included.

Trading cost: With the consideration of trading cost, the two model's profitability is slightly lower. Due to the shorter cycle of 4-day model, the trading cost is increased for more frequent transactions, and hence the profitability of 4-day model is lower than 5-day model in the downtrend interval.

\subsection{Statistical testing}

The testing result is listed in Table 4. The neural network prediction mode with largest total value of difference and rate of change is 5-day prediction. Furthermore, the MACD crossover 4-day prediction (multiplier $=4)$ mode has larger difference and total rate of change compared to traditional TIPP operation strategy and neural network prediction model. The modes with consideration of trading cost all have lower performance than the ones without cost consideration. Meanwhile, the total values of eight modes are all positive, which signifies the stable performance of this proposed model. Our testing result also shows that the overall performance of three models, in descending order, is MACD, ANN, and finally TIPP.

Table 4 Testing results of eight modes

\begin{tabular}{|c|c|c|c|c|c|c|}
\hline \multirow{2}{*}{$\begin{array}{c}\text { Total } \\
\text { Amount }(\Sigma)\end{array}$} & \multicolumn{3}{|c|}{ Difference } & \multicolumn{3}{|c|}{ Rate of change } \\
\hline & $\begin{array}{l}\text { ANN- } \\
\text { TIPP } \\
\end{array}$ & $\begin{array}{l}\text { MACD- } \\
\text { TIPP }\end{array}$ & $\begin{array}{l}\text { MACD- } \\
\text { ANN }\end{array}$ & $\begin{array}{l}\text { (ANN- } \\
\text { TIPP)' }\end{array}$ & $\begin{array}{l}\text { (MACD- } \\
\text { TIPP) }\end{array}$ & $\begin{array}{l}\text { (MACD- } \\
\text { ANN)' }\end{array}$ \\
\hline 4-day prediction & 548.32 & 3604.20 & 3055.88 & 7.81 & 30.32 & 22.52 \\
\hline $\begin{array}{l}\text { 4-day prediction; } \\
\text { trading cost } \\
\text { included }\end{array}$ & 441.04 & 3372.92 & 2931.88 & 7.03 & 28.58 & 21.56 \\
\hline 5-day prediction & 1098.74 & 3069.58 & 1970.84 & 10.53 & 24.05 & 13.52 \\
\hline $\begin{array}{c}\text { 5-day prediction; } \\
\text { trading cost } \\
\text { included } \\
\end{array}$ & 1051.98 & 2912.96 & 1860.97 & 10.17 & 22.84 & 12.67 \\
\hline $\begin{array}{c}\text { 4-day prediction; } \\
\text { multiplier }=4\end{array}$ & 548.32 & 7800.96 & 7252.64 & 7.81 & 63.06 & 55.25 \\
\hline $\begin{array}{l}\text { 4-day prediction; } \\
\text { multiplier }=4 ; \\
\text { trading cost } \\
\text { included }\end{array}$ & 441.04 & 7257.01 & 6815.97 & 7.03 & 58.89 & 51.86 \\
\hline \begin{tabular}{|c}
5 -day prediction; \\
multiplier $=4$
\end{tabular} & 1098.74 & 7025.90 & 5927.16 & 10.53 & 53.63 & 43.10 \\
\hline $\begin{array}{l}\text { 5-day prediction; } \\
\text { multiplier }=4 ; \\
\text { trading cost } \\
\text { included }\end{array}$ & 1051.98 & 6633.63 & 5581.65 & 10.17 & 50.47 & 40.30 \\
\hline
\end{tabular}

\section{Conclusion}

This work applies the TIPP to build an operation model. By adopting neural network to forecast future up/down trend of TaiEX, this work adjusts the multiplier of TIPP to pursue higher profits.

We simulate transactions according to the forecasts of the two neural networks, and an analysis is made to compare their performance. Our model concludes the following findings:

- Regardless of the trading cost, the MACD crossover forecast model has better performance than the traditional TIPP operation strategy in the bullish and bearish interval of TaiEX.

- Despite the 5-day forecast with trading cost, the MACD crossover roughly has equal performance with ANN forecast in the bearish interval of TaiEX. All the remaining MACD crossover modes outperforms ANN forecast.

- Despite the 5-day forecast of ANN forecast is slightly worse than traditional TIPP in the bullish interval of TaiEX, other ANN forecasts outperforms TIPP operation strategy.

- When augmenting the multiplier of MACD crossover to four, 4-day prediction is closer to the TaiEX uptrend scale than 5-day mode during the TaiEX bullish interval. The percentage of profit is $61.403 \%$ even the trading cost is included, which is close to the profit percentage of TaiEX, $64.114 \%$.

- When augmenting the multiplier of MACD crossover to four, the profitability of 5-day prediction is slightly higher than 4-day prediction during the TaiEX bearish interval. Contrary to the loss of buy and hold of TaiEX, both 4- and 5-day prediction have positive profitability no matter trading cost is included.

\section{References}

[1] Armano, Giuliano, et al. "Stock market prediction by a mixture of genetic-neural experts." International Journal of Pattern Recognition and Artificial Intelligence, Vol.16, pp.501-526, August, 2002.

[2] Black, Fisher, Jones, Rober, "Simplifying Portfolio Insurance", The Journal of Portfolio Management, pp.48-51,Fall 1987.

[3] Harrald, P.G., Kamstra, M., "Evolving artificial neural networks to combine financial forecasts." Evolutionary Computation, IEEE Transactions on , Vol.1, Iss. 1, pp. 40-52, April 1997.

[4] Phua, P.K.H., et al. "Neural network with genetically evolved algorithms for stocks prediction." Asia - Pacific Journal of Operational Research, Singapore, Vol. 18, Iss. 1; pp.103.May 2001.

[5] Tsaih, R., et al. "Forecasting S\&P 500 stock index futures with a hybrid AI system." Decision Support Systems, Vol.23, Iss. 2, pp.161-174, June, 1998. 